\title{
Regulation of Megakaryocyte Phenotype in Human Erythroleukemia Cells
}

Michael W. Long, Connie H. Heffner, J. Lynne Williams, Charles Peters, and Edward V. Prochownik* Division of Hematology/Oncology, Department of Pediatrics and Communicable Diseases, and the Committee on Cellular and Molecular Biology,* University of Michigan, Ann Arbor, Michigan 48109

\begin{abstract}
Induction of human erythroleukemia (HEL) cells with nanomolar tumor-promoting phorbol myristate acetate (PMA) diesters results in the synchronous acquisition of multiple markers of the megakaryocyte phenotype. Induced cells markedly increase their content of cytoplasm and show features of morphological maturation. At the ultrastructural level, PMAtreated cells show increases in cytoplasm, nuclear lobulation and nucleolar content, and free ribosomes. Limited numbers of cells also express $\alpha$-granules and nascent demarcation membrane systems. Functionally, PMA-stimulated HEL cells express increased amounts of the megakaryocyte/platelet proteins: glycoprotein IIb/IIIa, platelet factor 4, von Willebrand factor, glycoprotein Ib, and thrombospondin. No changes are observed in antigenic markers of the erythroid (glycophorin $A$ ) or macrophage lineages (MO-1 or MO-2). The increases in antigenic expression are rapid, reaching maximum levels within 3-4 d under serum-free conditions. Treatment with PMA also abruptly (within 1-2 d) inhibits cellular division in these cells. Washout studies indicate that phorbols exert their effect within 18-24 h, the approximate cell cycle time for these cells. Consistent with proliferative arrest, c-myc proto-oncogene transcripts begin to decline within $8 \mathrm{~h}$ of PMA treatment, although transcripts of c-myb are unaffected. Importantly, megakaryocyte differentiation is associated with endomitotic DNA synthesis (i.e., continued DNA synthesis in the absence of mitosis and cytokinesis), with HEL cells reaching a DNA content of 3-12 times that of unstimulated cells. Endomitosis is coordinately regulated with changes in antigenic expression and cell size such that those cells having the highest DNA content are the largest and also express the greatest levels of antigen. (J. Clin. Invest. 1990. 85:1072-1084.) differentiation - endomitosis • erythroleukemia • megakaryocyte • phorbol diester
\end{abstract}

\section{Introduction}

The study of lineage determination (commitment) during hematopoiesis is hindered by the unavailability of purified populations of multi- or pluripotent progenitor cells. Thus, examination of the intracellular events regulating hematopoietic de-

An abstract of portions of this paper was presented to the American Society of Hematology in December 1988.

Address reprint requests to Dr. Long, Pediatric Hematology/Oncology, Room 7510A, Box 0684, University of Michigan, Ann Arbor, MI 48109.

Received for publication 12 June 1989 and in revised form 17 November 1989.

J. Clin. Invest.

(C) The American Society for Clinical Investigation, Inc. $0021-9738 / 90 / 04 / 1072 / 13 \quad \$ 2.00$

Volume 85, April 1990, 1072-1084 termination requires the utilization of cell lines as models of the commitment process. Ideally, such cells should possess the capacity to develop into each of the myeloid lineages: granulocyte, erythrocyte, and megakaryocyte (platelet). Human erythroleukemia (HEL) ${ }^{1}$ cells are a triphenotypic cell line constitutively expressing an erythroid phenotype, but also expressing antigens of the other lineages (1-3). These cells increase their erythroid phenotype after stimulation with agents such as $\delta$-aminolevulinic acid (4). Similarly, an increase in macrophage phenotype occurs after high-dose $\left(10^{-6} \mathrm{M}\right) 4-\beta$ phorbol myristate acetate (PMA) treatment (5). Inducible changes in megakaryocyte/platelet-associated antigens have also been reported $(3,6-9)$. However, little information exists on the capacity of HEL cells to undergo full megakaryocyte development.

Megakaryocyte development begins with the response of an early progenitor cell to microenvironmental influences. These initiate developmental programs which culminate in a mature platelet-shedding megakaryocyte. The entire process is promoted at several points by soluble regulatory cytokines, each with distinct and, in some cases, overlapping targets (8, $10,11)$. Among these, the committed megakaryocyte progenitor cell and the immature megakaryocyte are the most sensitive to developmental signals, responding with predominantly proliferative or maturational development, respectively $(8,10$, 12). Ultimately, an understanding of the intracellular events mediating megakaryocyte lineage determination and development requires biological, biochemical, and molecular analysis of purified populations of each of these megakaryocyte subpopulations. Unfortunately, the paucity of mature megakaryocytes and their precursors, coupled with technical difficulties in purifying cells of this lineage, precludes the use of native megakaryocytes in such studies. Thus, the availability of inducible cell lines capable of undergoing early megakaryocyte differentiation represents an important tool for the examination of the intracellular events occurring during megakaryocytopoiesis.

We hypothesized that HEL cells would be an excellent model in which to study megakaryocyte development, having the advantages of being inducible, displaying a pluripotent phenotype (allowing determination of the lineage specificity of induction), and a demonstrable, albeit low, constitutive expression of some megakaryocytic properties. We report that HEL cells respond to low-dose tumor promoting phorbol diesters by developing into megakaryoblast-like cells. This de-

1. Abbreviations used in this paper: CI, confidence interval; DMS, demarcation membrane system; FALS, forward angle light scatter; HEL, human erythroleukemia cells; MSB, mean specific binding; NBT, nitroblue tetrazolium; PDBu, phorbol dibutyrate; PF4, platelet factor 4; Ib, IIb/IIIa, platelet glycoproteins Ib and IIb/IIIa; PMK-B, promegakaryoblast; SPA, staphylococcal protein A; SPRIA, solidphase radioimmunoassay; TSP, thrombospondin; vWF, von Willebrand factor; 7AAD, 7-aminoactomycin $\mathrm{D}$. 
velopment is associated with the synchronous expression of multiple megakaryocyte phenotypic markers. In particular, PMA-treated HEL cells undergo the process of endomitosis, a unique developmental feature of megakaryocytes.

\section{Methods}

\section{Cell cultivation and induction of differentiation}

HEL were cultivated in RPMI-1640 medium containing a $10 \%$ fetal calf serum (FCS; Hyclone Laboratories, Logan, UT), 1 mM pyruvate, and $2 \mathrm{mM}$ glutamate as described previously $(3,8)$. For studies on the induction of differentiation, HEL cells were grown to a density of 1.5 $\times 10^{6} \mathrm{cells} / \mathrm{ml}$, washed twice in phosphate-buffered saline (PBS), and cultivated at $1 \times 10^{5} \mathrm{cells} / \mathrm{ml}$ in the presence or absence (control) of tumor-promoting phorbol diesters. Unless otherwise stated, all induction studies were carried out under serum-free conditions in RPMI (as above) containing $1 \%$ bovine serum albumin (BSA, wt/vol; Sigma Chemical Co., St. Louis, MO). In certain instances, low-serum cultures were utilized which contained $0.5 \%$ FCS

Tumor-promoting phorbol diesters were prepared as described previously $(8,13,14)$. HEL cells respond to tumor-promoting phorbol diesters, but not to the parent alcohol (phorbol) nor to phorbol diesters, such as phorbol 12,13 diacetate, which lack tumor-promoting capacity, nor to the vehicle dimethyl sulfoxide (DMSO), which is $0.01 \%$ at $10^{-9}$ M PMA $(8,13,14)$.

\section{Morphological, cytochemical, and ultrastructural studies}

Morphological characterization was performed on May-Gruenwald/ Giemsa-stained cytocentrifuge preparations of HEL cells. Nitroblue tetrazolium (NBT)-reductase activity was examined utilizing a standard cytochemistry kit (Sigma Chemical Co., procedure No. 850); peripheral blood cells were used as a positive control. To preserve megakaryocyte morphology, HEL cells were collected in $5 \mathrm{vol}$ of CATCH (citrate, adenosine, theophylline containing calcium-free Hanks' solution) media (15), washed twice with $\mathrm{CATCH}$, and cytocentrifuged $\left(\sim 10^{5}\right.$ cells per slide). For electron microscopy, cells were fixed in $4 \% 0.1 \mathrm{M}$ cacodylate-buffered glutaraldehyde for $1 \mathrm{~h}$ at room temperature, washed twice in $0.1 \mathrm{M}$ cacodylate buffer, $\mathrm{pH}$. 7.4, postfixed in $2 \%$ cacodylate-buffered $\mathrm{OsO}_{4}$ for $1 \mathrm{~h}$ at room temperature, and washed twice in the $2 \%$ buffer. The cells were dehydrated in graded alcohol to propylene oxide, and infiltrated in graded concentrations of epon/propylene oxide for $\sim 3 \mathrm{~h}$. Cells were then pelleted in microfuge tubes, and embedded in pure epon utilizing gelatin capsules. The samples were hardened overnight at $65^{\circ} \mathrm{C}$. Plastic sections $(1.0 \mu \mathrm{m})$ were cut and stained with toluidine blue to identify areas of interest. Ultrathin sections were stained with uranyl acetate and lead citrate, and examined on an electron microscope (model 400T, Philips Electronic Instruments, Inc., Mahwah, NJ).

\section{Solid-phase radioimmunoassay (SPRIA) for hemopoietic cell antigens}

Changes in cellular antigenic expression were monitored by SPRIA utilizing a procedure developed in this laboratory (3). Briefly, cells were cultivated in the presence or absence of regulatory stimuli, and loaded directly into 96-well microfiltration plates (Milititer GV Durapore filter, Millipore Corp., Bedford, MA). All washes and antibody incubations were subsequently performed in situ. Specific binding is defined as the total radioactivity bound to antibody-labeled cells minus the radioactivity due to the nonspecific binding of ${ }^{125} \mathrm{I}$-staphylococcal protein A (SPA) to cells, or secondary antibody. Nonspecific binding was $<15 \%$ of the total binding for HEL cells (3). Controls run to determine nonspecific binding were ${ }^{125}$ I-SPA plus cells plus secondary antibody, and cells plus ${ }^{125}$ I-SPA. Additional controls were run for each assay to determine the nonspecific binding of primary antibody, secondary antibody, or ${ }^{125}$ I-SPA to the polyvinylidene membrane. These controls detect alterations in membrane binding characteristics, molecular complexing of antibody, etc. They are routinely $<1 \%$ of the nonspecific binding controls (3). All culture conditions were examined in triplicate SPIRA analysis, the values for which were averaged to yield a single culture value.

\section{Antibody specificity}

The megakaryocyte antibodies used in these studies were described previously $(3,8)$. These are antibodies to platelet factor 4 (PF4); von Willibrand factor (vWF); and platelet glycoprotein IIb/IIIa (IIb/IIIa), platelet glycoprotein Ib (Ib), and thrombospondin (TSP, a gift of Dr. Vishva Dixit, Department of Pathology, University of Michigan). Erythrocyte antigenic expression was monitored by the expression of glycophorin A (a gift of Dr. Stephen Emerson, Department of Internal Medicine, University of Michigan) and macrophage antigenic expression monitored by antibodies to the MO-1 or MO-2 antigen (16) (both gifts of Dr. Robert Todd III, Department of Internal Medicine, University of Michigan). The concentration of each antibody was as follows: anti-vWF, 1:1,000; anti-IIb/IIIa, 1:30; anti-Ib, 1:20; anti-TSP, 50 $\mu \mathrm{g} / \mathrm{ml}$; anti-glycophorin A, 1:1,000; anti-MO1 or $-\mathrm{MO} 2,1: 50$. For determination of total antigenic expression a cocktail of the megakaryocyte-specific antibodies was utilized (each at optimal concentration) (3).

\section{Proliferation studies}

The effects of differentiation inducers on cellular proliferation were monitored by determination of the proliferation index, defined as the -fold increase in total cells over the starting concentration $\left(10^{5}\right.$ cells/ $\mathrm{ml}$ ). All cultures contained equal volumes. Phorbol dibutyrate (PDBu) washout studies were performed as follows. HEL cells were grown as described above, washed three times in PBS, and preincubated in the presence of $10 \mathrm{nM}$ PDBu for the indicated times. Subsequently, cells were washed free of PDBu (three washes of PBS), resuspended in fresh media at the same concentration, and allowed to proliferate for $4 \mathrm{~d}$ (the usual induction time in serum free cultures; see below) after which the proliferation index was determined. Cell counts were performed in duplicate by hemocytometer.

\section{Analysis of proto-oncogene expression}

Tissue culture flasks (No. T-75, Corning Medical, Medfield, MA) of HEL cells were treated for different periods of time with $2 \times 10^{-9} \mathrm{M}$ PMA. Cells were harvested and total RNAs were prepared by the guanidine- $\mathrm{HCl}$ procedure. To detect c-myc transcripts, $10 \mu \mathrm{g}$ of total RNA from each time point were electrophoresed in a $1 \%$ agaroseformaldehyde gel, transferred to nitrocellulose (Schleicher \& Schuell, Inc., Keene, NH) and hybridized to a murine c-myc cDNA probe (17) labeled by random-priming (18) to a specific activity of $8 \times 10^{8}$ $\mathrm{dpm} / \mu \mathrm{g}$. To detect $\mathrm{c}$-myb-specific transcripts, we utilized a previously described S1 nuclease protection assay (19). In brief, a 1.5-kb Hind III fragment from the human c-myb expression vector, pMbml (19), was end-labeled with $\left.{ }^{32} \mathrm{P}\right]$ ATP using polynucleotide kinase to a specific activity of $\sim 7 \times 10^{7} \mathrm{dpm} / \mu \mathrm{g}$. Next, $2 \times 10^{5} \mathrm{dpm}$ of the probe were hybridized with $10 \mu \mathrm{g}$ of the total RNA as previously described (19). After digestion with $90 \mathrm{U}$ of S1 nuclease (Sigma Chemical Co., St. Louis, MO) the reaction products were resolved on a $1 \%$ agarose gel. The gel was dried and subjected to autoradiography using an intensifying screen.

\section{Determination of DNA content by flow cytometry}

DNA content was determined by flow cytometry utilizing 7-aminoactomycin $\mathrm{D}$ (7AAD) as described previously (20). This DNA probe has an emission optima of $650 \mathrm{nM}$ compared with $550 \mathrm{nM}$ for fluorescein, and thus allows simultaneous detection of DNA content and surface fluorescence utilizing FITC-conjugated antibodies on a single-laser cytometer. Briefly, cells were incubated with megakaryocyte-antibody cocktail (see above), and washed with Tris-PBS buffer ( $50 \mathrm{mM}$ trizma base, $4.7 \mathrm{mM} \mathrm{NaH}_{2} \mathrm{PO}_{4}, 16.0 \mathrm{mM} \mathrm{Na}_{2} \mathrm{HPO}_{4}, 119.8 \mathrm{mM} \mathrm{NaCl}$, and $1 \%$ BSA, pH 7.6). All antibody incubations and washes used Tris-PBS. Two washes were used after each step. Cells were sequentially incubated at room temperature with $6 \%$ goat serum $(30 \mathrm{~min}$; to block $\mathrm{Fc}$ 
receptors), primary antibody(ies) (30 min), FITC-conjugated secondary antibody or cocktail $(30 \mathrm{~min})$; affinity-purified anti-mouse Ig of appropriate isotype; (Cooper Biomedical/Cappel Laboratories, Malvern, PA). Antibody-labeled cells were fixed with dropwise addition of $70 \%$ ice-cold ethanol, and incubated in the dark $\left(90 \mathrm{~min}\right.$ at $\left.4^{\circ} \mathrm{C}\right)$ in 7 AAD $(25 \mathrm{mg} / \mathrm{ml})$, washed three times, and suspended in Tris-PBS. Cells were examined by flow cytometry usually in a single-laser cytometer (model C, Coulter Electronics, Inc., Hialeah, FL). For singlecolor (DNA) profiles, the antibody step was omitted. In certain instances, DNA content was determined in isolated nuclei, stripped of cytoplasm. For these studies, 7AAD was prepared in $100 \mathrm{mM}$ Trisbase containing $10 \mathrm{mM} \mathrm{NaCl}, 700 \mathrm{U} /$ liter RNAse, and $0.1 \%$ Nonidet P40 (NP40). Unless otherwise stated, flow histograms represent the acquisition of 40,000 cells. The DNA content was displayed on the abscissa utilizing a log-scale as megakaryocyte DNA content follows a log-normal distribution (21). Antibody binding was expressed on the ordinate (log-scale).

Cytometry. Cell fluorescence was analyzed using an Epics C (Coulter Electronics, Inc.) flow cytometer tuned to the 488-nm line of an argon laser. Emission wavelengths were separated with a $590-\mathrm{nm}$ dichroic mirror. Further filtering restricted measurement of FITC emission to the range $515-535 \mathrm{~nm}$, and 7AAD emission to above 610 $\mathrm{nm}$ (all filters and mirrors supplied by Coulter Electronics, Inc.). Forward angle light scatter (FALS) was used to gate out cell fragments and debris. As mentioned, a logarithmic scale was used to display 7AAD binding in order to capture the polyploid nature of the induced cells. For this reason, traditional cytometer cell cycle analysis methods cannot be performed, inasmuch as these require DNA acquisition on a linear scale. Instead, Stat Pack (a Coulter Electronics statistical analysis software program) was used to determine the frequency of cells in each peak (using the troughs between control sample peaks as natural dividing lines), by dividing the total number of cells in each peak by the total number of cells in the DNA histogram.

Autoradiography. To confirm that PMA-treated HEL cells were synthesizing DNA, cells were pulse-labeled with tritiated thymidine $\left(\left[{ }^{3} \mathrm{H}\right] \mathrm{TdR}\right.$, Amersham Corp., Arlington Heights, IL) according to the following protocol. Daily after exposure to $2.0 \mathrm{nM}$ PMA, cells were washed three times with PBS and pulsed with $\left[{ }^{3} \mathrm{H}\right] \mathrm{TdR}(6 \mu \mathrm{Ci} / \mathrm{ml} ; \mathrm{sp}$ act $40-60 \mathrm{Ci} / \mathrm{mM})$ in PBS for $30 \mathrm{~min}$ at $37^{\circ} \mathrm{C}$. Labeled cells were washed three times (PBS), cytocentrifuged onto glass slides, and fixed in absolute methanol. Incorporated $\left[{ }^{3} \mathrm{H}\right] \mathrm{TdR}$ was visualized utilizing Nuclear Track Emulsion (Type NTB 2, Eastman Kodak Co., Rochester, NY) per the manufacturer's instructions. Emulsion-coated slides were exposed for $5 \mathrm{~d}$, developed in D-19 developer (Eastman Kodak Co.), and stained for morphology as above.

\section{Statistics}

The sample number reported $(n)$ represents a number of individual experiments performed. For each experiment, all experimental conditions are cultured as two to three replicate cultures per condition. The data are expressed as mean \pm the $95 \%$ confidence interval $(95 \% \mathrm{CI})$ of the mean replicate culture values averaged over the indicate number $(n)$ of individual experiments.

Data normalization. To compare the kinetics and phorbol responsiveness of individual megakaryocyte antigens, the mean specific binding (MSB) RIA data were normalized as a percentage of peak increase in antigenic expression. The algorithm is as follows. For each antigen, the increase in antigenic expression is defined as the MSB of stimulated cells minus the MSB of control cells. The largest increase thus represents the peak (100\%) value. The other (lesser) values for that antigen are then normalized to the peak value and expressed as a percent.

Cytometry data. The relationship between megakaryocyte antigen expression, or cell size indicated by FALS, and DNA content was examined by converting the mean logarithmic signal to a linear equivalent, using a previously reported algorithm $(22,23)$. The mean specific antigen mean fluorescence content was then plotted vs. the mean DNA content.

\section{Results}

Morphological and ultrastructural changes occurring during PMA-induced megakaryocyte differentiation. In control cultures, HEL cells are deeply basophilic with a high nucleus/cytoplasm ratio (Fig. 1, $A$ and $B$ ) and a relatively uncomplicated nuclear structure. Also, rare $(<0.4 \%)$ large megakaryocytelike cells are observed (Fig. $1 \mathrm{~A}$, arrow). These cells retain their deep basophilia and high nucleus/cytoplasm ratio, but are increased in size and nuclear content. Within 3-5 d after PMA stimulation, HEL cells show a marked increase in cell size, cytoplasmic content, and nuclear complexity (Fig. $1 B$ ). The nuclei of these cells become larger and lobulated; the cytoplasm undergoes maturational changes becoming less basophilic and contains large regions of eosinophilia (contrast Fig. $1, C$ and $D$ ).

Ultrastructural examination of uninduced HEL cells indicated a fairly typical immature hematopoietic cell with a high nucleus/cytoplasm ratio and moderate mitochondrial and ribosomal content (Fig. 2 a). Examination of PMA-stimulated HEL cells by electron microscopy indicated a marked increase in cytoplasm, and an apparent increase in mitochondrial and free ribosome numbers, as well as lobulation of the nucleus (Fig. $2 b$ ). Additionally, membranous vesicles, which appear similar to regions of the nascent demarcation membrane system (DMS, which is felt to eventually delimit developing platelets; Fig. $2 b$ ), were seen in a few cells along with rare cells containing few $\alpha$-granule-like organelles (not shown).

Regulation of megakaryocyte antigen expression in HEL cells. After the induction of differentiation, quantitative changes occurred in the expression of megakaryocyte/plateletrelated proteins. Under serum-free conditions, low-dose PMA stimulation resulted in a significant increase (approximately sixfold above constitutive level) in the total amount of megakaryocyte antigen per cell (Fig. $3 \mathrm{~A}$ ). Significant increases occurred with as little as $0.3 \mathrm{nM}$ PMA and optimal antigenic expression was observed at $2 \mathrm{nM}$. No further increases in megakaryocyte antigens were seen at concentrations up to 50 $\mathrm{nM}$ (concentrations $>10.0 \mathrm{nM}$ not shown). Additionally, no alterations were seen over this range of PMA concentrations in the levels of macrophage antigens. The MO-1 antigen shows a constitutive binding of $248 \pm 98 \mathrm{pg} / 10^{5}$ total nucleated cells; (mean $\pm 95 \% \mathrm{CI} ; n=6$ ) and no significant increases were observed between 0.1 and $10.0 \mathrm{nM}$ PMA (e.g., expression at 10.0 $\mathrm{nM}$ is $317 \pm 142(n=8)$. The MO-2 antigen is not detected on HEL cells nor did increases in expression occur over this range of PMA stimulation (not shown). Similarly, glycophorin A showed low constitutive expression which did not alter with PMA treatment (not shown). As well, PMA-treated HEL cells (over a range of $0.1-10 \mathrm{nM}$ ) lack other macrophage characteristics; i.e., $90 \%$ of the cells are nonadherent and they are NBTreductase negative (not shown).

Analysis of individual antigen expression indicated that each reaches an optimum between 1.0 and $2.0 \mathrm{nM}$ PMA (Fig. $3 B$ ). No significant differential peak responsiveness was noted for any individual platelet protein. At optimal (1.0-2.0 nM) PMA concentrations, IIb/IIIa showed the greatest increase being 13-fold greater than constitutive levels, PF4 was 3.8 -fold increased, and TSP and vWF were 2.5 -fold increased (for normative values see Fig. 3 B, legend). TSP showed an increased sensitivity in the lower ranges of PMA concentrations (0.1-0.3 $\mathrm{nM})$. Ib gave the weakest signal of all among the megakaryo- 

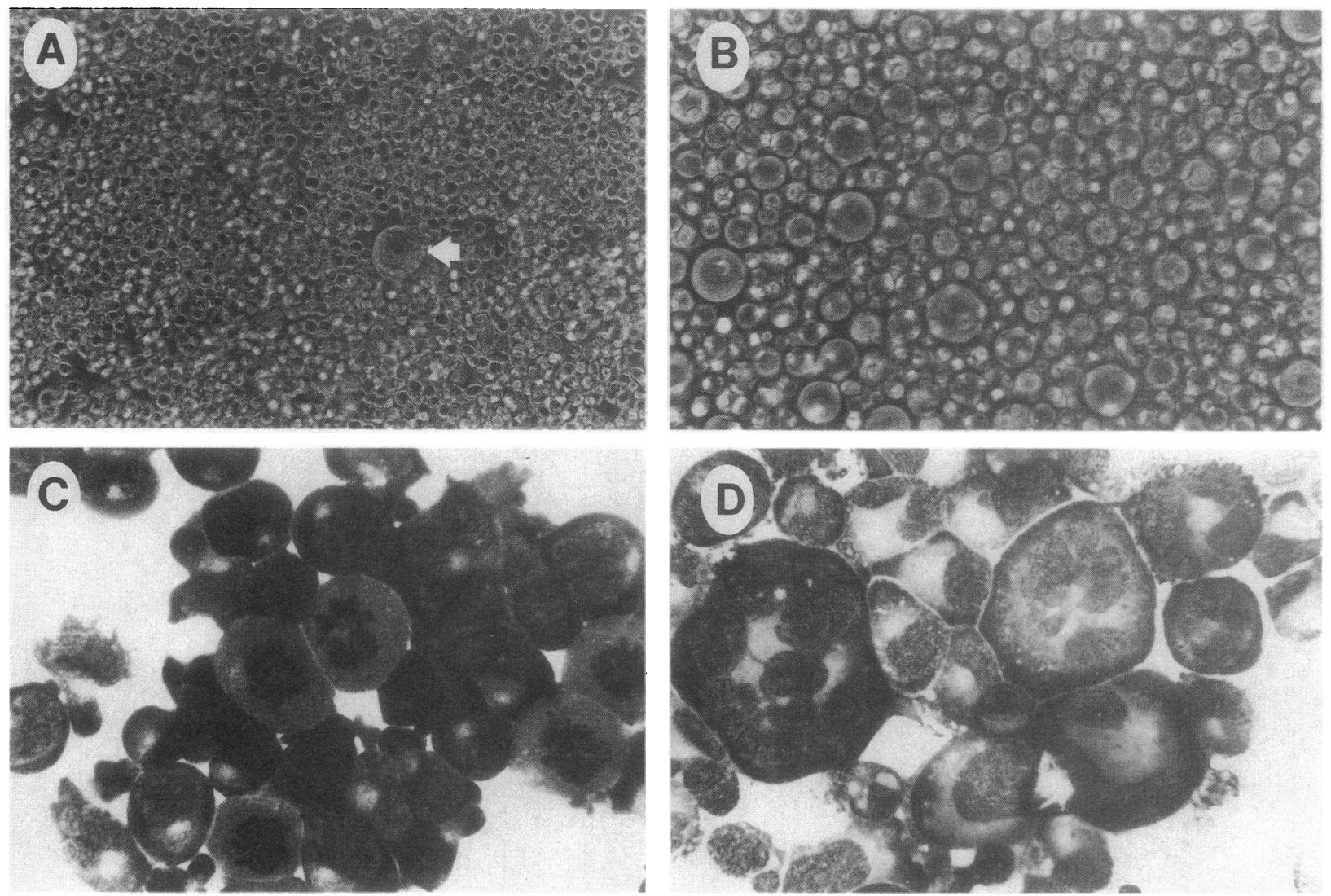

Figure 1. Morphology of PMA-stimulated HEL cells. Cells were incubated in the presence or absence of $10^{-9} \mathrm{M}$ PMA as described in the text. $(A)$ In situ phase-contrast photomicrograph of control (unstimulated) HEL cells. Note low frequency of large megakaryocyte-like cells (arrowhead) (original magnification $\times 10$ ). (B) Phase-contrast photomicrograph of PMA-stimulated HEL cells (original magnification $\times 50$ ). Note that photomicrographs $A$ and $B$ are at markedly different magnifications in order to demonstrate the frequency of megakaryocyte-like cells in unstimulated cell populations. Size differences are more readily apparent in $C$ and $D$ or Fig. 2. $(C)$ Photomicrograph of unstimulated Romanovskystained control HEL cells (original magnification $\times 400)$. (D) Photomicrograph of PMA-stimulated $\left(10^{-9} \mathrm{M}\right)$ HEL cells. Note increased cell size cytoplasmic content, reduced basophilia in perinuclear area, and increased nuclear complexity (original magnification $\times 400$ ).

cyte antigens tested, being undetectable in untreated cultures, but significantly (sixfold) elevated at $1.0 \mathrm{nM}$ PMA.

Studies on the rate of antigenic expression (at 2 nM PMA) in serum-free cultures demonstrated that the total content of megakaryocyte-related antigens significantly increased between days 2 and 3 of culture and reaches maximal levels of expression by day 4 (Fig. $4 A$ ). Individually, IIb/IIIa, PF4, Ib, and vWF all increased within 2-3 d of culture and reached maximal levels by day 4 (Fig. 4 B). TSP was the sole exception to this developmental process, reaching maximal expression within $48 \mathrm{~h}$ of exposure to PMA.

Unfortunately, prolonged incubation ( $\geq 5 \mathrm{~d}$ ) in serum-free cultures resulted in a loss in viability which was particularly evident in control (i.e., unstimulated) cultures. This low viability precluded the use of SPRIA studies due to nonspecific antibody binding. To examine later time periods, cultures were established which contained limiting amounts of serum ( $0.5 \%$ FCS). The addition of this small amount of serum improved viability in the controls, thus allowing analysis of maturation events occurring between days 4 and 10 of culture. Under these conditions, slight differences were noted in the kinetics of megakaryocyte antigen expression (not shown). Maximal antigenic expression in low-serum cultures was delayed by $\sim 3 \mathrm{~d}$ with maximal expression occurring on day 7 .
Presumably, this delay is due to the increased proliferative drive functioning in opposition to the differentiation effects of PMA (vide infra).

Cessation of proliferation as an index of terminal differentiation in PMA-treated HEL cells. Logarithmically growing HEL cells (i.e., cells grown in 10\% FCS during passage of the clone) increased 50-60-fold during $4 \mathrm{~d}$ of culture (not shown). These cells also proliferate in low-serum or serum-free cultures, although at greatly reduced rates (day 4 proliferation index $6.1 \pm 2.0(n=10)$ vs $31.7 \pm 3.4(n=12)$; mean $\pm 95 \% \mathrm{CI}$; for serum-free and low-serum cultures, respectively). After the induction of differentiation, HEL cells decreased both their rate and degree of proliferation (Fig. 5). This inhibition of proliferation was sharply dependent on PMA concentration. At PMA concentrations of $\leq 1 \mathrm{nM}$, no significant changes in proliferation index were observed compared to control, serum-free cultures (Fig. $5 \mathrm{~A}$ ). However, proliferation was significantly decreased at 2 nM PMA. HEL cells treated with 2 nM PMA have a proliferation index of 2.0 (in either serumfree or low-serum cultures, latter not shown) indicating that the treated cell population progressed through only a single round of proliferation after the induction of differentiation. The cessation of proliferation occurred between 2 and $3 \mathrm{~d}$ of culture after which no further proliferation is seen (Fig. $5 \mathrm{~B}$ ). 

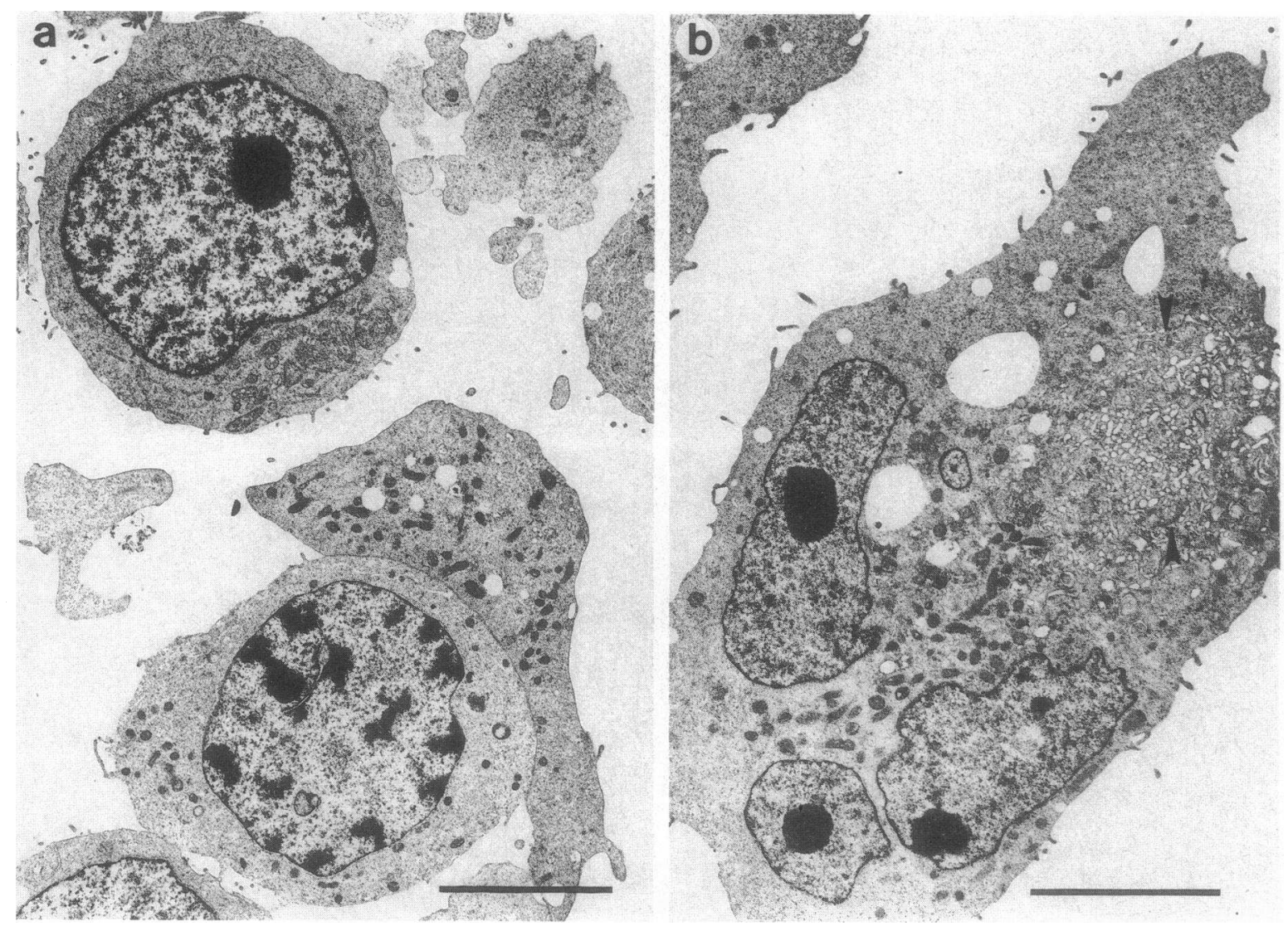

Figure 2. Ultrastructure of PMA-treated HEL cells. (a) Control HEL cell. Note high nucleus/cytoplasm ratio, relatively low organelle content, and immature nuclear structure (original magnification $\times 5,900$ ). (b) PMA-stimulated HEL cell. Responding cells show marked nuclear lobulation and increases in cytoplasmic content, ribosome content, and cytoplasmic organelles (original magnification $\times 6,600$ ). Note region of DMS. Developing DMS (between arrowheads) is seen in a small percentage of cells, is localized to the cytoplasm periphery, and is devoid of ribosomes. Bars, $10 \mu \mathrm{m}$.

Similar results occurred in low-serum cultures, with maximal inhibition occurring at $2 \mathrm{nM}$ PMA, but the time period required to reach this reduction was delayed until days 5-7 (not shown).

To more precisely determine the effect of phorbol diesters on proliferation, we took advantage of the hydrophilic nature of $\mathrm{PDBu}$, a tumor-promoting phorbol diester which is more readily washed out of cell membranes (24). Initial studies on the structure:activity relationship of PDBu indicated that HEL cells responded similarly to PMA or PDBu, but that the latter required $10 \mathrm{nM}$ concentrations to be biologically effective, presumably due to the lessened ability of this probe to intercalate into the cell membrane (24). Thus, PDBu washout experiments were performed to determine the precise time of exposure required to inhibit proliferation.

Exposure of HEL cells to $10 \mathrm{nM}$ PDBu for 4-8 h resulted in a $50 \pm 8 \%$ reduction in proliferation (mean $\pm 95 \% \mathrm{CI} ; n=3$ ) vs. unstimulated controls, whereas $16 \mathrm{~h}$ of exposure to PDBu resulted in a $89 \pm 4 \%$ reduction in proliferation. To determine the exact period of pretreatment required to reach maximal inhibition of proliferation, PDBu washout data was normalized to percentage of peak effect: i.e., each preincubation data point was expressed as the percentage of maximal PDBu inhibition. These data (Fig. $5 C$ ) show that maximal inhibition of proliferation occurred within $16 \mathrm{~h}$ of exposure to PDBu (the approximate cell cycle time for these cells), after which the inhibition of proliferation is complete.

Regulation of proto-oncogene expression in HEL cells. We next examined the expression of the c-myc and c-myb protooncogenes in HEL cells after PMA exposure. We chose to study these two genes in particular, as their expression has been shown to be important for both normal hematopoietic and leukemic cell proliferation (25-27). Furthermore, deregulated expression of either c-myc or c-myb has been shown to block the differentiation of some hematopoietic cell lines (28-31) although presumably through different mechanisms (32). RNAs were prepared from HEL cells treated for different periods of time with $2 \times 10^{-9} \mathrm{M}$ PMA. To study c-myc expression, a Northern blot containing equivalent amounts of RNA was probed with a ${ }^{32} \mathrm{P}$-labeled c-myc cDNA. The resultant autoradiogram showed equivalent c-myc transcript levels up to $4 \mathrm{~h}$ after the addition of PMA. Thereafter, the levels of c-myc mRNA declined and were barely detectable 2-3 d later (Fig. $6 \mathrm{~A}$ ). This decline of c-myc expression correlated well with the timing of the loss of HEL proliferative capacity based on PDBU washout studies. Interestingly, despite the profound loss of c-myc expression, cellular DNA synthesis was maintained as HEL cells underwent endomitosis (vide infra).

In contrast to c-myc, no significant changes in c-myb transcript levels were observed, even after the longest periods of 

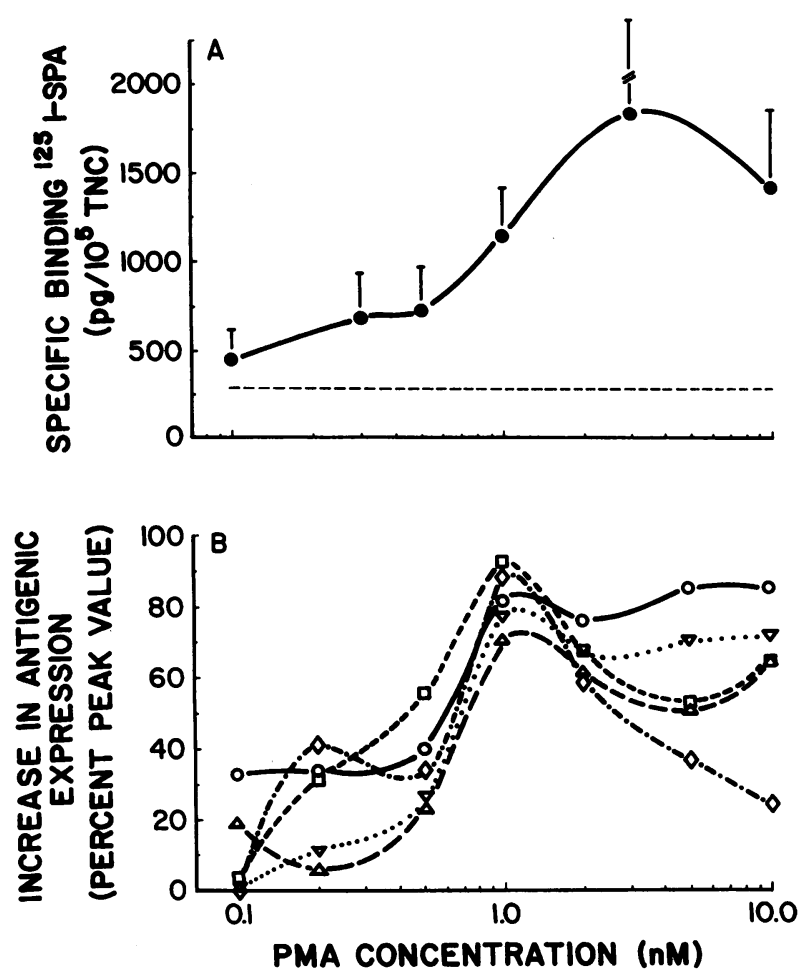

Figure 3. PMA-induced increases in megakaryocyte/platelet-associated proteins in HEL cells. $(A)$ Changes in total megakaryocyte antigen expression. HEL cells are cultured for $4 \mathrm{~d}$ under serum-free conditions as described in text. Values are mean $\pm 95 \% \mathrm{CI}(n=8-10)$ for PMA-treated cells (solid line and symbols). (Dashed line) Upper 95\% confidence interval for unstimulated (control HEL cells, $4 \mathrm{~d}$ in culture) $(n=21)$. Viability for both culture conditions is $>90 \%$ by trypan blue exclusion. $(B)$ Responsiveness of individual megakaryocyte antigens to varying concentrations of PMA. As the maximal antigenic content varies greatly for each, (see text) values were normalized to percent of peak increase in antigen expression for each antigen as described in Methods. The percent peak increase values are the means of three to four separate experiments (except for TSP which is six separate experiments). For simplicity, the $95 \% \mathrm{CI}$ are not shown. However, no significant differences in PMA-responsiveness are seen among the individual proteins and all are significantly elevated by $1.0 \mathrm{nM}$. The symbols and normative specific binding value (picograms of ${ }^{125}$ I-SPA bound per $10^{5}$ total nucleated cells) are as follows: IIb/IIIa (口) 1,627 pg; vWF ( $\nabla) 378$ pg; PF4 ( $\Delta$ ) 1,175 pg; TSP (०) $1,104 \mathrm{pg}$; and $\mathrm{Ib}(\diamond) 65 \mathrm{pg}$.

exposure to PMA (Fig. 6 B). These observations thus indicate a fundamental difference in the control of c-myb mRNA expression in HEL cells as compared to other leukemic cell lines where terminal differentiation is commonly associated with down-regulation of c-myb $(19,33,34)$.

Regulation of HEL cell DNA content. Utilizing flow cytometry to examine PMA-treated cells, we observed that HEL cells markedly increased their DNA content during phorbol-induced differentiation. To determine whether proliferative status influences polyploidization, we examined cells induced with $1.0 \mathrm{nM}$ PMA (at which no detectable reduction in proliferation occurs) and $2 \mathrm{nM}$ (at which the cells cease to proliferate). After $7 \mathrm{~d}$ of culture, control cells demonstrated a DNA distribution equivalent to that of a predominantly quiescent cell population (Fig. 7). The exception was a small number $(\sim 10 \%)$ of HEL cells that constitutively committed to mega-
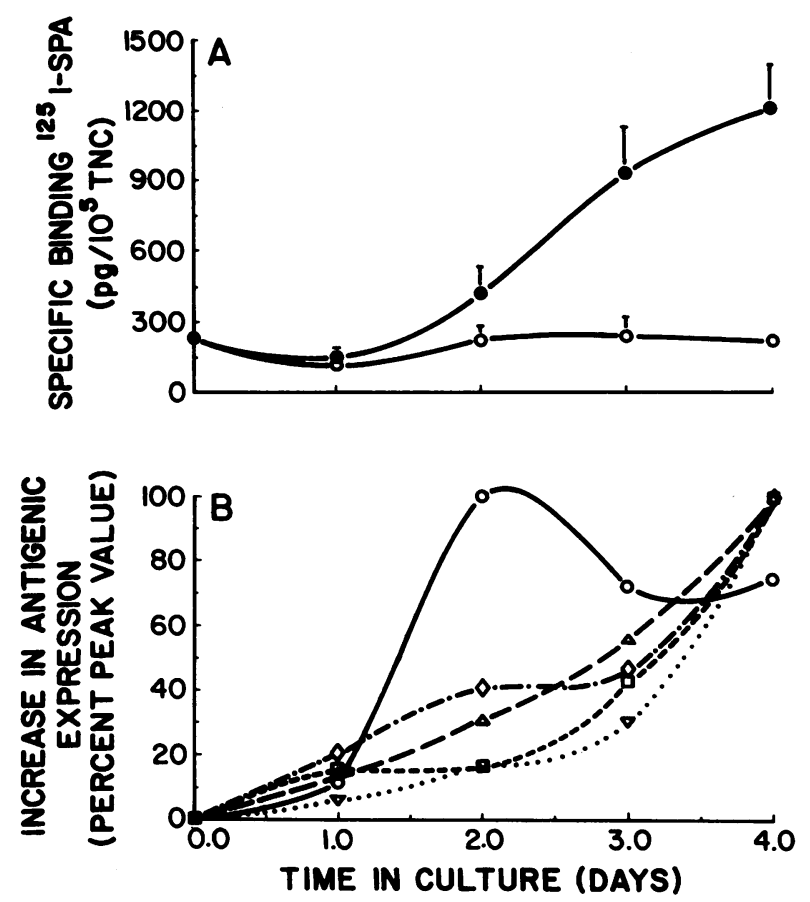

Figure 4. Kinetics of HEL cell megakaryocyte antigen expression. HEL cells cultivated for 1-4 d under serum-free conditions in the presence of $2 \mathrm{nM}$ PMA, as described in the text. $(A)$ Changes in total megakaryocyte antigen expression. (๑) PMA-treated cells. (०) Control (unstimulated cells). Values are mean $\pm 95 \% \mathrm{CI}$ of two to three separate experiments normalized (see Methods) to percent peak increase. $(B)$ Changes in individual antigen expression. Normative values (i.e., day 4) and symbols are given in Fig. 3, except for TSP in which $100 \%$ equals an increase of $1,478 \mathrm{pg} / 10^{5}$ total nucleated cells which occurs on day 2. No significant differences are observed (by $95 \% \mathrm{CI}$; not shown) between IIb/IIIa, vWF, PF4, and Ib. Thrombospondin is significantly elevated, both over controls and in contrast to other megakaryocyte proteins, by $48 \mathrm{~h}$ in culture.

karyocyte endomitosis and thus contained a DNA content greater than that of cells in $\mathbf{G}_{2} / \mathrm{M}$ phase of the cell cycle (Fig. 7). These relatively quiescent HEL cell populations (cultivated $7 \mathrm{~d}$ under low-serum conditions) contained $\sim 62 \%$ of the cells in $G_{0} / G_{1}, 10 \%$ in S-phase, $18 \%$ in $G_{2} / M$, and $<10 \%$ greater than $G_{2} / M$. Stimulation of HEL cells with $1 \mathrm{nM}$ PMA shifted these cells into DNA synthesis as analysis of these DNA profiles indicated that $\sim 20 \%$ of the PMA-stimulated cells retain a DNA content equivalent to that of $G_{0} / G_{1}$ control cells. Alternatively, PMA may stimulate a phenotypic change in the $G_{0} / G_{1}$ phenotype such that the cells exhibit an increased fluorescence (of $1.5 \mathrm{C}$ ), thus reducing the actual percentage of cells remaining in $G_{0} / G_{1}$. Our data do not distinguish between these alternatives. However, the ratio of cells in $G_{0} / G_{1}$ to those having a greater than $G_{0} / G_{1}$ DNA content is 20:80 in PMAinduced cells, whereas in controls it was 60:40. While the significance of the frequency of cells remaining in $G_{0} / G_{1}$ is unclear, demonstrable PMA-induced increases in the percentage of cells having a greater DNA content than $G_{2} / M$ are seen in single-color DNA analysis (control cells are $8.0 \pm 1 \%$ greater than $G_{2} / M, 1$ nM PMA $25.2 \pm 7 \%, 2$ nM PMA 33.0 $\pm 7 \%$, values are mean $\pm 95 \% \mathrm{CI} ; \boldsymbol{n}=7$ ). Further, PMA-treated cells showed stepwise twofold increases in DNA content relative to control $G_{0} / G_{1}$ DNA content; these cells contain 1.5-, 3-, 6-, 

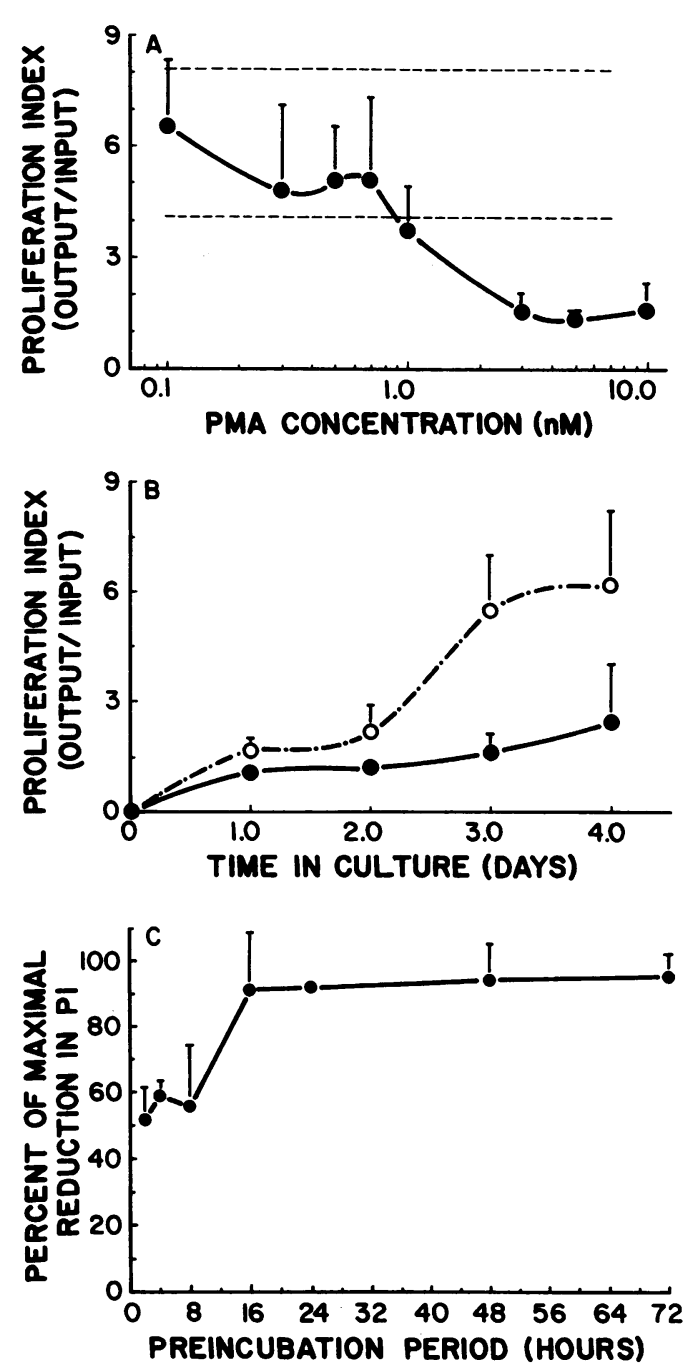

Figure 5. Alterations in HEL cell proliferation after PMA stimulation. Cells cultured under serum free conditions as described in text. Proliferation index is defined as the increase in total culture cellularity over the starting population of $1 \times 10^{5} \mathrm{HEL}$ cells $/ \mathrm{ml}$. (A) Alterations in proliferation in response to varying PMA concentrations. HEL cells were treated serum-free with varying concentrations of PMA and cellularity determined on day 4 . Values are mean $\pm 95 \% \mathrm{CI}$ of 5-10 separate experiments. (Dashed lines) The upper and lower 95\% confidence intervals for control (unstimulated) HEL cells cultured for $4 \mathrm{~d}$. (B) Kinetics of phorbol diester-induced proliferation changes in HEL cells. Control cells (O) and cells stimulated with 2.0 nM PMA (•) were examined daily for $4 \mathrm{~d}$. Values are mean $\pm 95 \% \mathrm{CI}$ $(n=8)$. (C) PDBu washout studies. HEL cells were preincubated in the presence of $10 \mathrm{nM}$ PDBu for the indicated times, washed three times in PBS, resuspended in fresh culture media (without PDBu), and allow to proliferate for a total of $4 \mathrm{~d}$ after which proliferation index is determined. Values are mean $\pm 95 \% \mathrm{CI}(n=3)$.

and 12-fold increases in DNA content (these data were confirmed in two-color cytometry studies, vide infra).

The cytometric data showing an increase in DNA content over $7 \mathrm{~d}$ implied that PMA-treated cells continued to synthesize DNA during differentiation. This was confirmed using pulse-label $\left[{ }^{3} \mathrm{H}\right] \mathrm{TdR}$ incorporation studies. These data showed that, after a $30-$ min pulse, $9.7 \%$ of PMA-treated HEL cells incorporate $\left[{ }^{3} \mathrm{H}\right] \mathrm{TdR} 24 \mathrm{~h}$ after stimulation. Pulse-label incor-
A
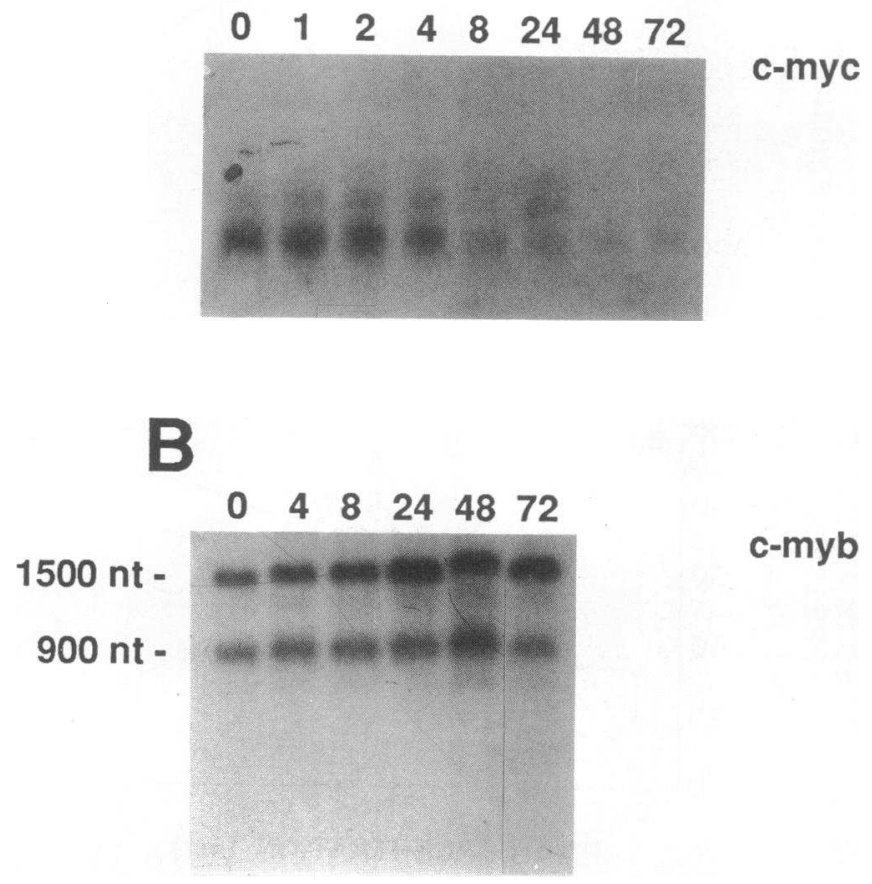

Figure 6. Levels of c-myc and c-myb proto-oncogene transcripts in PMA-stimulated HEL cells. Individual flasks of HEL cells $(\sim 5$ $\times 10^{5}$ cells $/ \mathrm{ml}$ ) were treated with $2 \times 10^{-9} \mathrm{PMA}$. Aliquots of cells were removed at the times indicated above each lane and the RNAs purified. To detect c-myc transcripts (Fig. $6 A$ ) $10 \mu \mathrm{g}$ of each RNA were electrophoreses in a $1 \%$ agarose-formaldehyde gel and transferred to a Nytran membrane. The blot was then hybridized with a murine c-myc cDNA insert (31), and labeled with $\left[^{32} \mathrm{P}\right] \mathrm{dCTP}$ by the random priming method (18) to a sp act of $\sim 7 \times 10^{8} \mathrm{dpm} / \mu \mathrm{g}$. To detect c-myb transcripts (Fig. $6 \mathrm{~B}$ ) an $\mathrm{S} 1$ nuclease protection assay was used (19). A 1.5-kb Hind III restriction fragment from the human c-myb expression plasmid pMbml (19) was end labeled with $\left.{ }^{32} \mathrm{P}\right] \mathrm{ATP}$ and polynucleotide kinase to a sp act of $\sim 10^{7} \mathrm{dpm} / \mu \mathrm{g}$. The blot was then hybridized with $10 \mu \mathrm{g}$ of each RNA, digested with $90 \mathrm{U}$ of $\mathrm{S} 1$ nuclease, and resolved on a $1 \%$ agarose gel as previously described (19). Authentic endogenous c-myb transcripts protect an $\sim 900$-nt fragment of the input probe.

poration peaked at $48-72 \mathrm{~h}$ at $15.0 \%$ and was sustained at 10-11\% until day 7 . For comparison, density-arrested, quiescent control cells showed $5.3 \%$ incorporation. (These values are the means of triplicate determinations per data point, on a single experiment.) These pulse-label studies indicated that, at any given 30 -min interval, at least $15 \%$ of the PMA-treated cells were synthesizing DNA. However, flow cytometric analysis demonstrated that, cumulatively, over $50 \%$ of the cells underwent sustained DNA synthesis (see subsection Coordinate Regulation. . . below).

Lack of cell fusion as a mechanism of increased DNA content. Data from a number of observations provide evidence that the increase in DNA content is not due to cell fusion. While admittedly a weak tool, morphological analysis of a large number of induced HEL cells (by live-cell phase-contrast microscopy as well as Romanovski staining) shows no evidence of cells in the process of cellular fusion. Additionally, $\sim 90 \%$ of the induced cells contain the lobulated nucleus typi- 

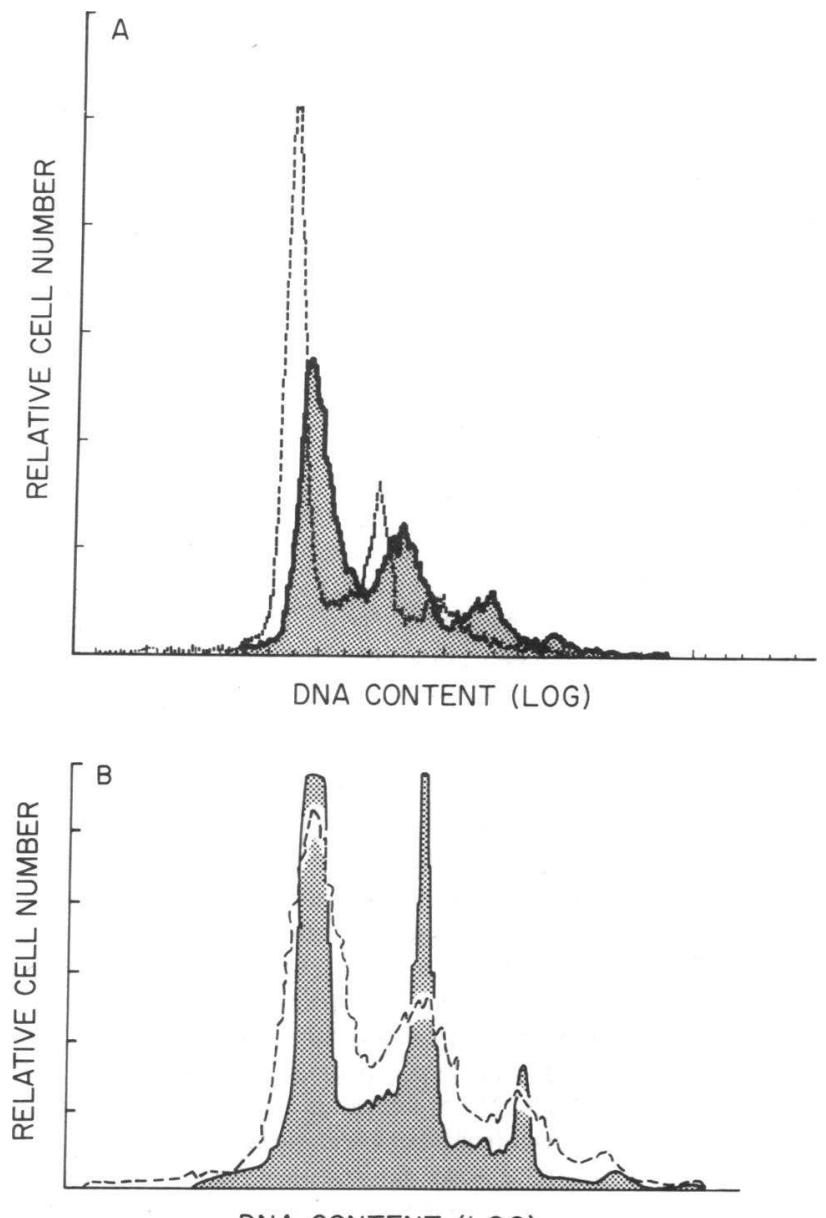

DNA CONTENT (LOG)

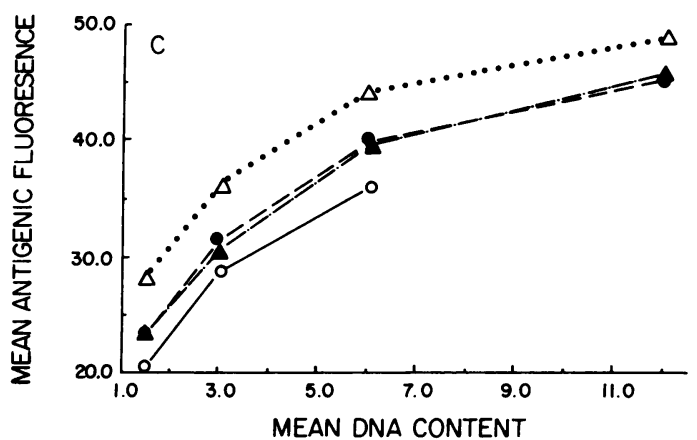

Figure 7. DNA content in PMA-stimulated HEL cells. HEL cells were grown in low-serum $(0.5 \%)$ conditions for $7 \mathrm{~d}$ and analyzed for DNA content as described in Methods. $(A)$ DNA content of control and PMA-stimulated cells. Both control cell DNA content (dashed lines, open profile) and cells stimulated with $1.0 \mathrm{nM}$ PMA (solid line stippled profile) are run as separate determinations and electronically overlaid using the standard Coulter Epics $C$ cytometer graphics program. (B) Comparison of the PMA-stimulated DNA content of intact HEL cells and isolated HEL cell nuclei. Phorbol diester (2.0 nM PMA)-stimulated HEL cells were cultivated as above and intact cells or cell stripped of cytoplasm (see Methods) analyzed for DNA content. No loss of higher ploidy classes are seen in isolated nuclei (solid line, stippled profile) compared to intact cells (dashed line, open profile), nor do the percent of cells within each ploidy class change. Similar observations are seen in cells stimulated with 1.0, 3.0, and 5.0 nM PMA (not shown). The increase in breadth of the intact cell profile is due to the known increase in the coefficient of variation in flu- cal of megakaryocytes, and not multiple nuclei (morphological data not shown). We directly explored the role of fusion in elevated DNA content by comparing the DNA content of both intact cells and cells stripped of cytoplasm (i.e., isolated nuclei). We hypothesized that if the polyploidy cells were multinuclear, then stripping the cytoplasm would result in a loss of the high ploidy classes with the redistribution of these nuclei to the $2 \mathrm{C}$ class, resulting in an increase in $2 \mathrm{C}$ frequency. This does not occur, as the two types of DNA analyses are equivalent (Fig. 7 B). As well, analysis of the percentage of cells within each ploidy class indicates no significant differences between intact cells and isolated nuclei in PMA-treated or control cells (not shown). We further reasoned that if cellular fusion occurs, then the process must be random and result in integer fusions, with $2,3,4,5, \cdots n$ cells fusing into a single cell. This implies both that the relationship between antigen and DNA content should be linear, and that fused cells will show integer increments (and not twofold multiples) in DNA content. As demonstrated in Fig. $7 C$, the relationship between megakaryocytic antigen expression and DNA content is not linear. More importantly, the macrophage antigen MO1 and the erythroid antigen glycophorin A (see subsection Regulation of Megakaryocyte Antigen Expression above) are expressed at constant levels, do not show increased expression after low-dose PMA induction, and thus do not follow the predicted linear relationship with DNA content. The failure of these two antigens to show a linear (or any) increase in expression coupled with the exponential increase in megakaryocytic antigens is, in itself, a powerful argument against fusion. Moreover, the DNA histograms presented in Figs 7, $A$ and $B$, and 8 clearly reveal that DNA increases occur in twofold multiples and not integer increments. Finally, both flow cytometric (Fig. 8 , vide infra) and autoradiographic analysis of $\left[{ }^{3} \mathrm{H}\right] \mathrm{TdR}$ labeled HEL cells indicate that PMA-induced cells synthesize DNA for 5-7 d in culture. The cytometric data indicates a logarithmic increase in DNA content occurs, again ruling out fusion. Autoradiographic analysis demonstrates that the grain count per cell is homogeneously distributed over the nucleus and is of high intensity. This homogeneous distribution pattern again excludes fusion in that fused cells (or nuclei) would show variably labeled, multiple nuclei or a large, fused nucleus with a nonhomogeneous grain distribution. Neither of these alternatives occurs. The above data thus establish that cell fusion is not the mechanism of either increased DNA content, or increased antigenic expression.

Coordinate regulation of megakaryocyte DNA content, antigen expression, and cell size. In order to prove conclusively that those HEL cells having an increased megakaryocyte anti-

orescence emission when using DNA probes in intact cells (20). The DNA profiles are from a single representative experiment of six separate experiments. $(C)$ Relationship of mean megakaryocyte antigen expression to mean relative DNA content. HEL cells were grown as above and stimulated with $2.0 \mathrm{nM}$ PMA, and intact cells were analyzed for antigen expression and DNA content by flow cytometry as described in Methods. The data are expressed as the mean antigenic fluorescence for each ploidy class (ordinate, see Methods and [22, 23]) vs. the mean ploidy value (abscissa). Cells were stimulated for 3 $\mathrm{d}(\mathrm{O}), 5 \mathrm{~d}(\bullet), 7 \mathrm{~d}(\Delta)$, and $10 \mathrm{~d}(\Delta)$. The data presented in $C$ are derived from the two-color profiles shown in Fig. 8, right-hand column (2 nM PMA). 

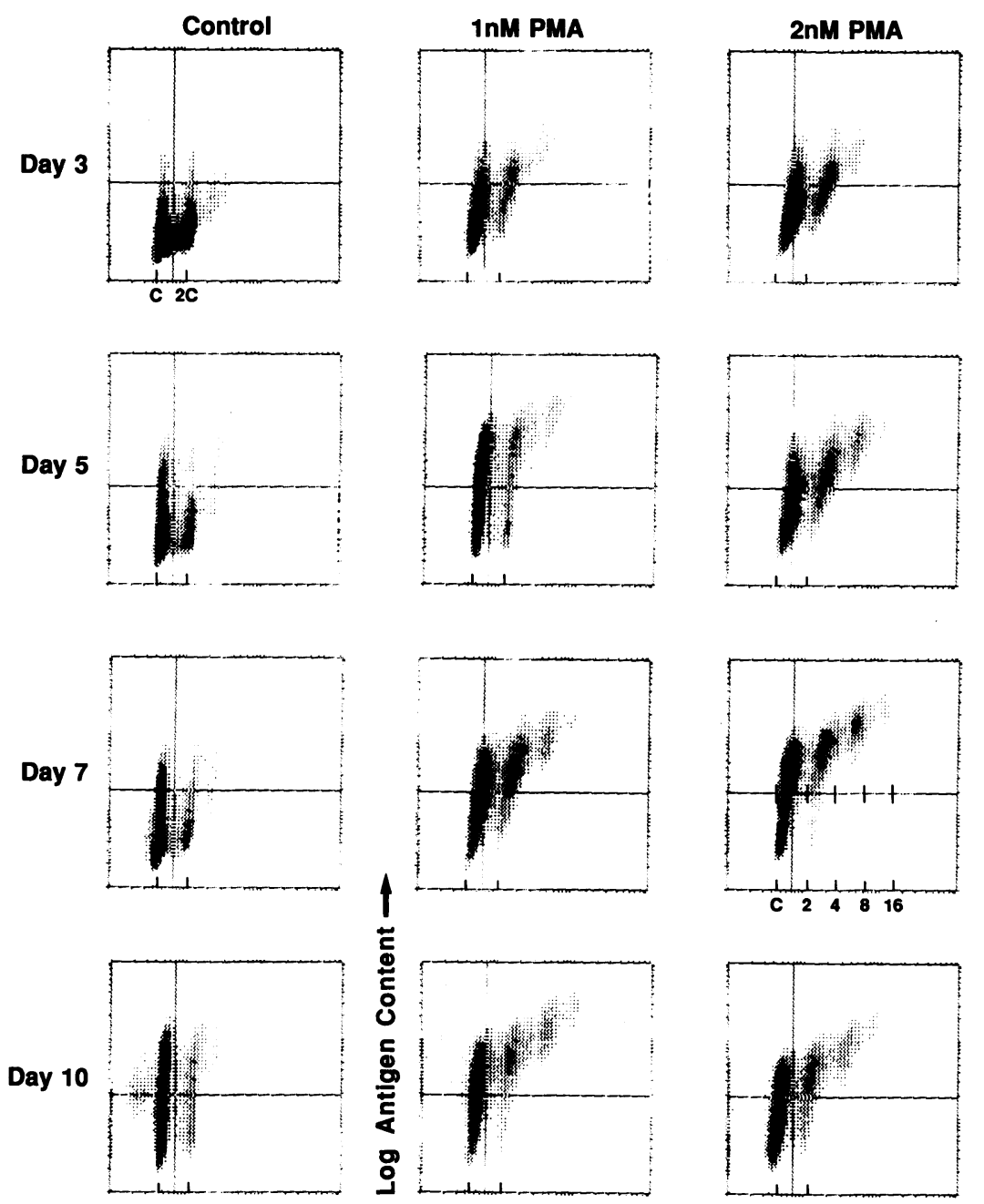

Log DNA Content

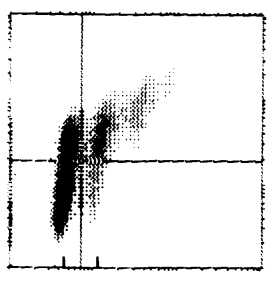

Figure 8. Simultaneous DNA and megakaryocyte protein expression in HEL cells. HEL cells were cultured as described in Fig. 7 and analyzed for DNA content (7AAD) and total megakaryocyte protein expression (megakaryocyte antibody cocktail; FITC-labeled secondary antibody; see Methods). Results are a single representative experiment of two separate kinetics experiments. Each profile represents the acquisition of $\sim 4 \times 10^{4}$ cells. $C$, the arbitrary DNA content of HEL cells in the $\mathrm{G}_{0} / \mathrm{G}_{1}$ phase of the cell cycle; $2 C$ (etc.), a twofold increase in DNA content. Tick marks are thus the $C$ and $2 C$ channel positions for each profile except day 7, 2 nM PMA which shows tick marks at $C$, $2 C, 4 C, 8 C$, and $16 C$. The $x$-cursor (vertical bar) is positioned on day 3 control cells to mark the upper limits of the $G_{0} / G_{1}$ population (as obtained on single-color DNA analysis of the same population). The $y$-cursor (horizontal bar) is positioned such that $95 \%$ of the day 3 control cells are below this level of antigen expression as determined by antibody-specific fluorescence. Cursor positions are left unchanged for the remaining 11 determinations, to allow easy visualization of changes in DNA antigen content. gen expression are also those which acquire an increased DNA content, two-color flow cytometry was performed to correlate antigenic expression and DNA content in the same cell. As illustrated in Fig. 8, cells expressing the highest DNA content also expressed the greatest amount of megakaryocyte antigen. In contrast, examination of the control cells over a 10-d culture period showed a slight, gradual increase in antigenic expression without detectable changes in DNA content. After exposure to $1 \mathrm{nM}$ PMA, total antigenic content began to elevate by day 3 , and reached maximal levels between days 5 and 7 , thus confirming the observations obtained by SPRIA. Along with increasing antigenic expression, HEL cells concomitantly increased their DNA content with notable changes first occurring between days 3 and 5 . Subsequently, HEL cells continued to increase their DNA content until day 10 when over $50 \%$ of the cells had both an elevated DNA content and high levels of antigen expression. Stimulation with $2 \mathrm{nM}$ PMA resulted in a similar pattern in antigenic expression. However, the increased PMA concentration caused an earlier increase in DNA synthesis (detectable by day 3), and maximal DNA content was achieved between days 5 and 7. Subsequently, these cultures had decreased numbers of cells in the high antigen, high DNA category due to cellular degradation. At 2 nM, PMA-stimulated HEL cells also acquire twofold multiples of their original
$\left(G_{0} / G_{1}\right)$ DNA content with increases in DNA content equivalent to that of $1 \mathrm{nM}$ PMA. Notably, these increases were only in the populations which also showed an increased antigen content.

We next examined the relationship between DNA content and cell size, using FALS as an index of cell size. As do normal megakaryocytes, PMA-treated HEL cells show a positive correlation between DNA content and cell size (FALS). Similar to studies of antigenic expression, those cells with the highest DNA content also are the cells with the largest FALS or size (Fig. 9). Thus, DNA content, cells size, and antigenic expression are all coordinately regulated in response to phorbol diesters.

\section{Discussion}

HEL cells have a primitive, mixed, hematopoietic cell phenotype, expressing surface antigens of the erythroid, macrophage, and megakaryocyte lineages. We observed that treatment of these cells with low-dose phorbol diesters $\left(\sim 10^{-9} \mathrm{M}\right)$ results in an increased degree of commitment to the megakaryocytic lineage. Morphologically, PMA-stimulated cells increase their size, degree of cytoplasmic maturation, and nuclear complexity. Ultrastructural analysis shows further evidences of early 


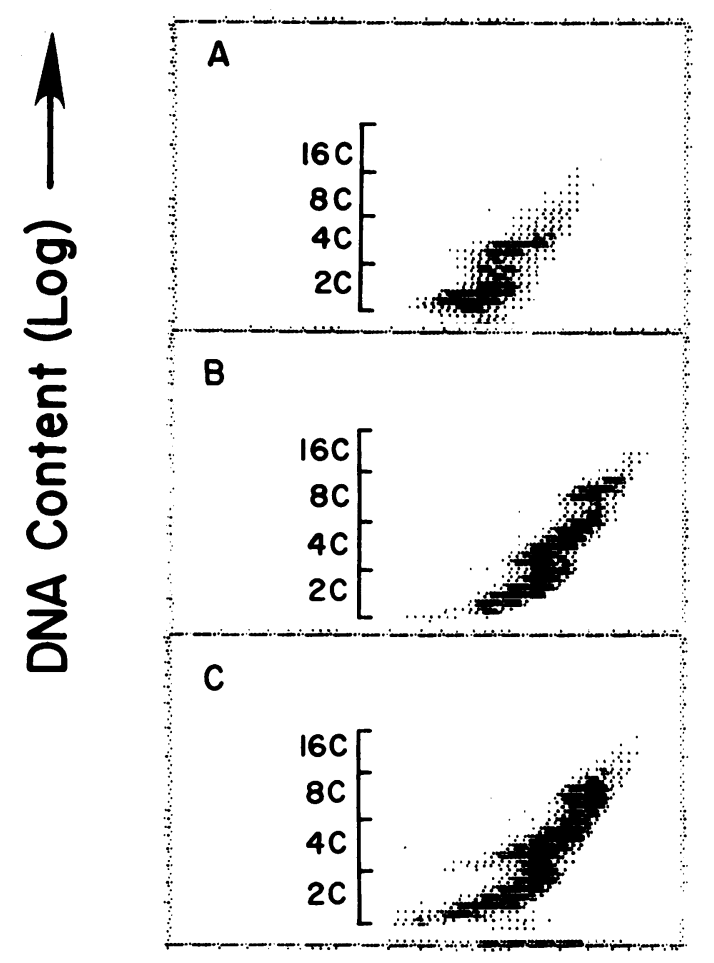

\section{Forward Angle Light Scatter

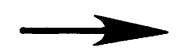

Figure 9. Relationship of HEL cell DNA content to FALS (cell size) HEL cells were cultivated as in Fig. 7 and analyzed for total megakaryocyte protein expression as in Fig. 8. Results are a single representative experiment of two separate experiments. Control and PMA-stimulated cells were analyzed $7 \mathrm{~d}$ after induction $(2.0 \mathrm{nM}$ PMA). Each profile represents the acquisition of $\sim 4 \times 10^{4}$ cells. The horizontal brackets represent the range of the ploidy intervals $(C)$ as defined in Fig. 8 and Methods. $(A)$ control (unstimulated) cells; $(B$ and $C$ ) 2.0 nM PMA-stimulated cells in serum-containing and serum-free media, respectively.

megakaryocytic commitment: nascent DMS and limited numbers of $\alpha$-granules. Functionally, HEL cells respond to phorbol diesters by increasing surface expression of various megakaryocyte-platelet associated proteins: IIb/IIIa, vWF, PF4, Ib, and TSP. These changes are accompanied by declines in c-myc but not c-myb proto-oncogene transcripts. Phorbol-treated HEL cells also abruptly cease proliferating, but continue to increase their DNA content, with some cells obtaining a DNA content 12-fold greater than the resting $\left(G_{0} / G_{1}\right)$ state. This process of prolonged DNA synthesis is coordinately linked with changes in antigenic expression and cell size such that cells showing the greatest DNA concentration also have the highest degree of antigenic expression, and largest cell size.

Morphological examination of PMA-treated HEL cells reveals an increase in the degree of cytoplasmic maturation which is indicated by a marked reduction in basophilia and an increase in eosinophilia. Ultrastructural observations demonstrate increases in cytoplasm, nuclear complexity, and free ribosomes. Moreover, the nuclei of stimulated cells become lobulated and show increased numbers of nucleoli. These morphological and ultrastructural observations are consistent with HEL cells reaching a maturation stage equivalent to that of either the promegakaryoblast or megakaryoblast. The promegakaryoblast (PMK-B), as defined by Breton-Gorius and co-workers (35), is a small, morphologically unrecognizable megakaryocyte distinguished by its ultrastructure and the expression of platelet/megakaryocyte-associated antigenic markers $(35,36)$. Ultrastructurally, these immature megakaryocytes contain large amounts of rough endoplasmic reticulum, numerous mitochondria, ribosomes, and are devoid of $\alpha$ granules, with limiting amounts (if any) of DMS (35). Megakaryoblasts are more mature than the PMK-B and represent the earliest megakaryocyte recognizable by light microscopy $(35,37)$. Ultrastructurally, megakaryoblasts have increased amounts of DMS and contain easily identifiable $\alpha$-granules (35). Our data shows that PMA-stimulated HEL cells acquire a phenotype which is intermediate between these two maturational stages. The increase in cytoplasmic content, cell size, and nuclear complexity (as well as functional data, vide infra) is consistent with the megakaryoblast stage, but the limitations in DMS development and $\alpha$-granule synthesis correlate best with the PMK-B. The failure or limitation in the ability of these cells to synthesize $\alpha$-granules or DMS is not surprising as colony-derived megakaryocytes and, in particular, immature megakaryocytes grown in culture tend to lack these structures (35).

Coupled with morphological changes, HEL cells markedly increase the expression of platelet/megakaryocyte-associated proteins in response to PMA. This expression is rapid reaching maximal levels within 3-4 d under serum-free conditions. With the exception of thrombospondin, which responds early and shows increased PMA sensitivity, the individual platelet proteins follow a synchronous developmental program reaching optimal expression at identical times and PMA concentrations. These observations corroborate similar studies showing that HEL cells constitutively express megakaryocyte antigens and that these antigens respond to phorbol diesters $(6,9)$. In particular, Tabilio et al. (6) have correlated the expression of platelet membrane and $\alpha$-granule proteins with morphological and ultrastructural changes. Their observations are consistent with those reported here, but did not show coordinate changes in DNA content, regulation of antigen expression, oncogene expression, and morphological phenotype. Our observations of low expression (either constitutive or induced) of $\mathrm{Ib}$ are corroborated by that of Kieffer and co-workers (7). Their data show that HEL cells express a Ib-like protein which is an incompletely or abnormally $\boldsymbol{O}$-glycosylated Ib $\alpha$-subunit.

Our data also show that HEL cells constitutively express macrophage and erythroid antigens and that these antigens are not altered by low-dose (1-10 nM) PMA. Interestingly, Papayannopoulou and co-workers (5) have shown that high-dose phorbol diesters $\left(10^{-6} \mathrm{M}\right)$ induce morphological, functional, and biochemical changes in HEL cells which are characteristic of macrophage-like cells (5). The mechanism by which PMA regulates both macrophage and megakaryocyte differentiation in these cells is unknown. However, PMA is pleiotrophic in its effects, and at high concentrations significantly alters membrane function (24). Further, protein kinase $C$, the intracellular ligand for PMA, is a heterogeneous protein with multiple subspecies (38). It may be that the multiple forms of protein kinase $\mathrm{C}$ and/or other signal transduction systems such as ade- 
nylate cyclase synergistically function to regulate commitment to one or the other of these lineages (39).

Further work by Papayannopoulou et al. (40) on the regulation of HEL cell erythroid phenotype indicates that stimulation of (numerous) erythroleukemia cell lines results in the developmental expression of primitive globin programs (i.e., fetal or embryonic), but never a fully differentiated erythroid phenotype. They suggest that these programs are either aberrant because of leukemic transformation, or more likely, represent differentiation programs which normally are resident at earlier stages of development in normal progenitor cells (40). These studies also point to the close relationship between erythroid and megakaryocytic phenotypic expression in erythroleukemic cell lines and suggest that this close association may be of relevance in normal differentiation. Our data corroborate and extend these observations by showing that HEL cells, which are predominantly of an erythroid phenotype in the resting state, can be induced to fully commit to the megakaryocytic lineage without apparent alterations in the degree of macrophage/erythrocyte phenotype.

Megakaryocytes are unique among mammalian marrow cells in that they leave the diploid state to differentiate, synthesizing 4-32 times the normal DNA content within a single nucleus (a process known as endomitosis) (21). The onset of this process occurs following the proliferative phases of development but is antecedent to the development of the earliest morphologically recognizable cell, the megakaryoblast (41, 42 ). While abnormal in the sense of not having a typical $2 \mathrm{C} / 4 \mathrm{C}$ cycle of DNA replication, megakaryocyte endomitosis is tightly regulated. With each replicative event the entire DNA content is duplicated such that megakaryocytes have twofold multiples of a normal diploid cell content (i.e., 4, 8, 16, and 32 times the normal somatic cell DNA content) $(21,43-46)$. Thus, DNA synthesis in these cells is released from normal cell cycle control, but global control over replication is retained. Phorbol-treated HEL cells go through successive increases in DNA content reaching levels as high as 12 times that of their resting DNA content within a 3-5 d period. Given that proliferation ceases within the first $24 \mathrm{~h}$ of PMA stimulation and DNA synthesis continues, these cells (like normal megakaryocytes) are undergoing endomitosis. HEL cells therefore approximate the endomitotic program of normal megakaryocytes and are thus an important model for examining the endomitotic process. However, as is the case for other megakaryocyte characteristics, the process of endomitosis is not complete. In contrast to normal megakaryocytes, HEL cells synthesize less than the expected DNA content (i.e., less than the typical 2-, 4-, 8-, and 16-fold increases in DNA content seen in normal cells). The paucity of megakaryocytes in the marrow ( $\leq 0.06 \%$ of the nucleated cells) and the technical difficulties in purifying either mature or, in particular, immature megakaryocytes makes studies on the control of this endomitosis process difficult, if not impossible. Thus, the identification of an endomitotic process in a cell line such as HEL cells represents an important development for study of this aspect of megakaryocyte differentiation.

A number of cell lines exist which, unlike HEL cells, are restricted to the megakaryocyte lineage (47-49). It must be realized that each of the cell lines expressing an inducible megakaryocyte phenotype and some ability to execute endomitosis (HEL, EST-IU, Meg-01, and Dami) shows basal changes in DNA content (polyploidy), chromosome content (multiple trisomies), and chromosome structure (numerous translocations) (1, 47-49). Some unknown component of these alterations may therefore predispose these cells to megakaryocyte differentiation. While trisomy seems to be the basis for the hyperdiploid DNA content of unstimulated cells, the activation of endomitosis (at least in HEL cells) results in replicative doubling of the DNA content of these cells-as evidenced by its successive doubling of the DNA content in response to PMA. Endomitosis, as a component of megakaryocyte differentiation, therefore initiates normally but, in contrast to normal megakaryocytes, is incomplete.

The finding of marked decreases in c-myc content of differentiating HEL cells in intriguing. C-myc levels commonly decline with the onset of terminal differentiation in a number of different model systems $(33,50,51)$. As terminal differentiation is, by definition, accompanied by a cessation of DNA synthesis, some investigators have speculated that c-myc may be involved in this latter process $(52,53)$. The unique ability of HEL cells to initiate endomitosis in the face of drastically lowered c-myc levels argues that the c-myc gene product is not required for DNA synthesis.

The actions of tumor-promoting phorbol diesters in inducing megakaryocyte differentiation suggest that the acquisition of a megakaryocyte phenotype as well as the endomitotic alteration in DNA synthesis, are mediated by protein kinase $C$, a calcium-dependent, serine-threonine protein kinase, which is the intracellular target for PMA $(24,54)$. Our data show that the requirement for this differentiation signal is transient, irreversible (after 16-18 h), and results in the cessation of proliferation followed by the synchronous acquisition of a megakaryocyte phenotype. All of these observations are consistent with the activation of protein kinase C. Similarly, we previously demonstrated that both normal human megakaryocyte progenitor cells (8) as well as immature murine megakaryocytes (14) differentiate in the presence of phorbol diesters, which suggests that similar differentiation mechanisms exist in normal megakaryocytopoiesis. However, the association of differentiation with protein kinase $\mathrm{C}$ is limited by the known pleiotropic effects of PMA (55-58) and the ability of protein kinase $\mathrm{C}$ to modulate other signal transduction systems (39). In this regard, other data from our laboratory (using a murine system) document a role for adenylate cyclase in the proliferation of murine megakaryocyte progenitor cells $(59,60)$.

End-stage maturational events such as the formation of an extensive demarcation membrane system, completion of endomitosis, and $\alpha$-granule synthesis are observed in only a few PMA-stimulated HEL cells, and division of the cytoplasm into platelet fields does not occur. This suggests that either the entire megakaryocyte maturation program is not activated by phorbol diesters, or that these cells are incapable of full megakaryocytic differentiation. Such a failure of terminal differentiation frequently is noted in inducible hematopoietic cell lines. For example, the progranulocytic cell line, HL60, when induced to granulocyte formation with DMSO, does not express myeloperoxidase-related killing, lacks lactoferrin, and shows abnormalities in lactate dehydrogenase isozymes (51). Similarly, HEL cells when induced to erythroid differentiation synthesize fetal but not adult globins (4).

We conclude that human erythroleukemia cells can commit to megakaryocyte lineage, as shown by the coordinate expression of numerous megakaryocyte phenotypic markers: megakaryocyte-associated antigens, lineage-specific morpho- 
logical and ultrastructural changes, and, importantly, the acquisition of an endomitotic DNA content. The pluripotent HEL cell line is thus an excellent model for examining the processes of lineage determination in hematopoietic cells because it shows inducible alterations in the macrophage, erythrocyte, and megakaryocyte phenotype. Importantly, these cells are a valuable model for understanding early events in megakaryocyte development such as regulation of platelet protein expression, or the intriguing process of endomitosis.

\section{Acknowledgments}

The authors are indebted to Dr. Vishva Dixit for discussions and suggestions on the manuscript and Jennie McAlpine for careful preparation of the manuscript.

This study was supported in part by grants HL-31568 and HL-35225 from the National Institutes of Health. Michael W. Long is a scholar of the Leukemia Society of America. Edward V. Prochownik is an Established Investigator of the American Heart Association.

\section{References}

1. Martin, P., and T. Papayannopoulou. 1982. HEL cells: a new human erythroleukemia cell line with spontaneous and induced globin expression. Science (Wash. DC). 216:1233-1235.

2. Papayannopoulou, T., T. Yokochi, B. Nakamoto, and P. Martin. 1983. The surface antigen profile of HEL cells. In Globin Gene Expression and Hematopoietic Differentiation. G. Stamatoyannopoulous, and G. Neinhuis, editors. Alan R. Liss, Inc., New York. 277-292.

3. Long, M. W., and C. H. Heffner. 1988. Detection of human megakaryocyte antigens by solid-phase radioimmunoassay. Exp. Hematol. 16:62-70.

4. Papayannopoulou, T., B. Nakamoto, S. Kurachi, and R. Nelson. 1987. Analysis of the erythroid phenotype of HEL cells: clonal variation and the effect of inducers. Blood. 70:1764-1772.

5. Papayannopoulou, T., B. Nakamoto, T. Yokochi, A. Chait, and R. Kannagi. 1983. Human erythroleukemia cell line (HEL) undergoes a drastic macrophage-like shift with TPA. Blood. 62:832-845.

6. Tabilio, A., J. P. Rosa, N. Kieffer, A. T. Nurden, M. C. Del Canizo, J. Breton-Gorius, and W. Vainchenker. 1984. Expression of platelet membrane glycoproteins and alpha-granule proteins by a human erythroleukemia cell line (HEL). EMBO (Eur. Mol. Biol. Organ.) J. 3:453-459.

7. Kieffer, N., N. Debili, A. Wicki, M. Titeux, A. Henri, Z. Mishal, J. Breton-Gorius, W. Vainchenker, and K. J. Clemetson. 1986. Expression of platelet glycoprotein Ib alpha in HEL cells. J. Biol. Chem. 261:15854-15862.

8. Long, M. W., R. J. Hutchinson, L. L. Gragowski, C. H. Heffner, and S. G. Emerson. 1988. Synergistic regulation of human megakaryocyte development. J. Clin. Invest. 82:1779-1786.

9. Papayannopoulou, T., E. Raines, S. Collins, B. Nakamoto, M. Tweeddale, and R. Ross. 1987. Constitutive and inducible secretion of platelet-derived growth factor analogues by human leukemic cell lines coexpressing erythroid and megakaryocytic markers. J. Clin. Invest. 79:859-866

10. Lu, L., R. A. Briddell, C. D. Graham, J. E. Brandt, E. Bruno, and R. Hoffman. 1988. Effect of recombinant and purified human haematopoietic growth factors on in vitro colony formation by enriched populations of human megakaryocyte progenitor cells. $B r . J$. Haematol. 70:149-156.

11. Bruno, E., M. E. Miller, and R. Hoffman. 1989. Interacting cytokines regulate in vitro human megakaryocytopoiesis. Blood. 73:671-677.

12. Long, M. W., N. Williams, and S. Ebbe. 1982. Immature megakaryocytes in the mouse: physical characteristics, cell cycle status, and in vitro responsiveness to thrombopoietic stimulatory factor. Blood. 59:569-575.

13. Long, M. W., L. L. Gragowski, C. H. Heffner, and L. A. Boxer. 1985. Phorbol diesters stimulate the development of an early murine progenitor cell: the burst-forming unit-megakaryocyte. J. Clin. Invest. 67:431-438.

14. Long, M. W., J. E. Smolen, P. Szczepanski, and L. A. Boxer. 1984. Role of phorbol diesters in in vitro murine megakaryocyte colony formation. J. Clin. Invest. 74:1686-1692.

15. Levine, R. F., and M. E. Fedorko. 1976. Isolation of intact megakaryocytes from guinea pig femoral marrow: successful harvest made possible with inhibitors of platelet aggregation; Enrichment achieved with a two-step separation technique. J. Cell Biol. 69:159172.

16. Todd, R. F., and S. F. Schlossman. 1982. Analysis of antigenic determinants on human monocytes and macrophages. Blood. 59:775-786.

17. Stanton, L. W., P. D. Fahrlander, P. N. Tesser, and K. B. Marcu. 1984. Nucleotide sequence comparison of normal and translocated murine c-myc genes. Nature (Lond.). 310:423-425.

18. Feinburg, A. P., and B. Vogelstein. 1983. High specific activity labeling of DNA restriction endonuclease fragments. Anal. Biochem. 132:6-13.

19. Clark, M. F., J. F. Kukowska-Latallo, E. Westin, M. Smith, and E. V. Prochownik. 1988. Constituative expression of a c-myb cDNA blocks Friend murine erythroleukemia cell differentiation. Mol. Cell. Biol. 8:884-892.

20. Rabinovitch, P. S., R. M. Torres, and D. Engel. 1986. Simultaneous cell cycle analysis and two-color surface immunofluorescence using 7-amino-actinomycin D and single laser excitation: applications to study of cell activation and the cell cycle or murine LY-1 B cells. $J$. Immunol. 136:2769-2775.

21. Odell, T. T., Jr., C. W. Jackson, and D. G. Gosslee. 1965. Maturation of rat megakaryocytes studied by microspectrophotometric measurement of DNA. Proc. Soc. Exp. Biol. Med. 119:1 194-1199.

22. Todd, R. F., P. A. Alvarez, D. A. Brott, and D. Y. Liu. 1985. Bacterial lipopolysaccharide, phorbol myristate acetate, and muramyl dipeptide stimulate the expression of a human monocyte surface antigen, Mo3e. J. Immunol. 135:3869-3877.

23. Muirhead, K. A., T. C. Schmitt, and A. R. Muirhead. 1983. Determination of linear fluoresence intensity from flow cytometric data accumulated with logarithmic amplifiers. Cytometry. 3:565.

24. Nishizuka, Y. 1984. The role of protein kinase $C$ in cell surface signal transduction and tumour promotion. Nature (Lond.). 308:693698.

25. Prochownik, E. V., J. F. Kukowska Latallo, and C. Rogers. 1988. C-myc antisense transcripts accelerate differentiation and inhibit G1 progression in murine erythroleukemia cells. Mol. Cell Biol. 8:3683-3695.

26. Wickstrom, E., T. A. Bacon, A. Gonzalez, D. L. Freemen, and G. H. Lyman. 1988. Human promyelocytic leukemia HL-60 cell proliferation and c-myc protein expression are inhibited by an antisense pentadecadeoxynucleotide targeted against c-myc RNA. Proc. Natl. Acad. Sci. USA. 85:1028-1032.

27. Gewirtz, A. M., and B. Calabretta. 1988. A c-myb antisense oligodeoxynucleotide inhibits normal human hematopoiesis in vitro. Science (Wash. DC). 242:1303-1306.

28. Coppola, J. A., and M. D. Cole. 1986. Constitutive c-myc oncogene expression blocks mouse erythroleukemia cell differentiation but not commitment. Nature (Lond.). 320:760-763.

29. Dmitrovsky, E., W. H. Kuehl, G. F. Hollis, I. R. Kirsch, T. P. Bender, and S. Segal. 1986. Expression of a transfected human c-myc oncogene inhibits differentiation of a mouse erythroleukemia cell line. Nature (Lond.). 322:748-750.

30. Lachman, H. M., G. Cheng, and A. I. Skoultchi. 1986. Transfection of mouse erythroleukemia cells with myc sequences changes the rate of induced commitment to differentiation. Proc. Natl. Acad. Sci. USA. 83:6480-6484. 
31. Prochownik, E. V., and J. F. Kukowska. 1986. Deregulated expression of c-myc by murine erythroleukemia cells prevents differentiation. Nature (Lond.). 822:848-850.

32. Prochownik, E. V. 1989. c-myb but not c-myc suppresses the hemin-induced non-terminal expression of hemoglobin by Friend erythroleukemia cells. Blood. 73:782-786.

33. Gonda, T. J., and D. Metcalf. 1989. Expression of myb, myc, and fos proto-oncogenes during the differentiation of a murine myeloid leukemia. Nature (Lond.). 310:249-251.

34. Westin, E. H., R. C. Gallo, S. K. Arya, A. Eva, L. M. Souza, M. A. Baluda, S. A. Aaronson, and F. Wong-Staal. 1982. Differential expression of the AMV gene in human hematopoietic cells. Proc. Natl. Acad. Sci. USA. 79:2194-2198.

35. Breton-Gorius, J., and W. Vainchenker. 1986. Expression of platelet proteins during the in vitro and in vivo differentiation of megakaryocytes and morphological aspects of their maturation. Semin. Hematol. 23:43-67.

36. Marie, J. P., J. P. Vernant, B. Dreyfus, and J. Breton-Gorius. 1979. Ultrastructural localization of peroxidases in 'undifferentiated' blasts during the blast crisis of chronic granulocytic leukaemia. $\mathrm{Br}$. $J$. Haematol. 43:549-558.

37. Long, M. W., and N. Williams. 1981. Immature megakaryocytes in the mouse: Morphology and quantitation acetylcholinersterase staining. Blood. 58:1032-1039.

38. Nishizuka, Y. 1988. The molecular heterogeneity of protein kinase $\mathrm{C}$ and its implications for cellular regulation. Nature (Lond.). 334:661-665.

39. Yoshimasa, T., D. R. Sibley, M. Bouvier, R. J. Lefkowitz, and M. G. Caron. 1987. Cross-talk between cellular signalling pathways suggested by phorbol-ester-induced adenylate cyclase phosphorylation. Nature (Lond.). 327:67-70.

40. Papayannopoulou, T., B. Nakamoto, S. Kurachi, M. Tweeddale, and H. Messner. 1988. Surface Antigenic profile and globin phenotype of two new human erythroleukemia cell lines: characterization and interpretation. Blood. 72:1029-1038.

41. Feinendegen, L. E., N. Odartchenko, H. Cottier, and V. P. Bond. 1962. Kinetics of megakaryocyte proliferation. Proc. Soc. Exp. Biol. Med. 111:177-182.

42. Ebbe, S. 1976. Biology of megakaryocytes. Prog. Hemostasis Thromb. 3:211-229.

43. Odell, T. T., Jr., and C. W. Jackson. 1968. Polyploidy and maturation of rat megakaryocytes. Blood. 32:102-110.

44. De Leval, M. 1968. Etude cytochimique quantitative des acides desoxyribunucleiques au cours de la maturation megacaryocytaire. Nouv. Rev. Fr. Hematol. 88:392-394.

45. Tomer, A., L. A. Harker, and S. A. Burstein. 1988. Flow cytometric analysis of normal human megakaryocytes. Blood. 71:12441252.

46. Corash, L., J. Levin, Y. Mok, and J. McDowell. 1989. Measure- ment of megakaryocyte frequency and ploidy distribution in unfractionated murine bone marrow. Exp. Hematol. 17:278-286.

47. Sledge, G. W., Jr., M. Glant, J. Jansen, N. A. Heerema, B. J. Roth, M. Goheen, and R. Hoffman. 1986. Establishment in long-term culture of megakaryocytic leukemia cells (EST-IU) from the marrow of a patient with leukemia and a mediastinal germ cell neoplasm. Cancer Res. 46:2155-2159.

48. Ogura, M., Y. Morishima, R. Ohno, Y. Kato, N. Hirabayashi, H. Nagura, and H. Saito. 1985. Establishment of a novel human megakaryoblastic leukemia cell line, MEG-01, with positive Philadelphia chromosome. Blood. 66:1384-1392.

49. Greenberg, S. M., D. S. Rosenthal, T. A. Greeley, R. Tantravahi, and R. L. Handin. 1988. Characterization of a new megakaryocytic cell line: the DAMI cell. Blood. 72:1968-1977.

50. Lachman, H. M., and A. I. Skoultchi. 1984. Expression of c-myc changes during differentiation of mouse erythroleukemia cells. Nature (Lond.). 310:592-594.

51. Collins, S. J. 1987. The HL-60 promyelocytic leukemia cell line: proliferation, differentiation, and cellular oncogene expression. Blood. 70:1233-1244.

52. Classon, M., M. Henriksson, J. Sumegi, G. Klein, and M. L. Hammaskjold. 1987. Elevated c-myc expression facilitates the replication of SV40 DNA in human lymphoma cells. Nature (Lond.). 330:272-274.

53. Iguchi-Ariga, S. M., T. Itani, M. Yamaguchi, and H. Ariga. 1987. c-myc protein can be substituted for SV40 T antigen in SV 40 DNA replication. Nucleic Acids Res. 15:4889-4899.

54. Niedel, J. E., L. J. Kuhn, and G. R. Vandenbark. 1983. Phorbol diester receptor copurifies with protein kinase C. Proc. Natl. Acad. Sci. USA. 80:36-40.

55. Nakaki, T., S. Mita, S. Yamamoto, T. Nakadate, and R. Kato. 1984. Inhibition by palmitoylcarnitine of adhesion and morphological changes in HL-60 cells induced by 12-O-tetradecanoylphorbol-13-acetate. Cancer Res. 44:1908-1912.

56. Kreutter, D., A. B. Caldwell, and M. J. Morin. 1985. Dissociation of protein kinase $C$ activation from phorbol ester-induced maturation of HL60 leukemia cells. J. Biol. Chem. 260:5979-5984.

57. Blumberg, P. M., S. Jaken, B. Konig, N. A. Sharkey, K. L. Leach, A. Y. Jeng, and E. Yeh. 1984. Mechanism of action of the phorbol ester tumor promoters: specific receptors for lipophilic ligands. Biochem. Pharmacol. 33:933-940.

58. Bishop, W. R., and R. M. Bell. 1986. Attenuation of sn-1,2diacylglycerol second messengers. Metabolism of exogenous diacylglycerols by human platelets. J. Biol. Chem. 261:12513-12519.

59. Long, M. W., C. H. Heffner, and L. L. Gragowski. 1988. Cholera toxin and phorbol diesters synergistically modulate murine hematopoietic progenitor cell proliferation. Exp. Hematol. 16:195-200.

60. Long, M. W. 1989. Signal transduction events in In Vitro megakaryocytopoiesis. Blood Cells (Berl.). 15:205-235. 